\title{
Adult Diffuse Astrocytoma
}

National Cancer Institute

\section{Source}

National Cancer Institute. Adult Diffuse Astrocytoma. NCI Thesaurus. Code C7174.

A low grade (WHO grade II) astrocytoma occurring during adulthood. It is characterized by a high degree of cellular differentiation, slow growth, and diffuse infiltration of neighboring brain structures. 